\title{
Diagnosis challenges in a uterine leiomyosarcoma
}

\author{
Raluca Balan*,1,2, Corina Andriescu ${ }^{1,3}$, Diana Popovici ${ }^{1,2}$, loana Păvăleanu ${ }^{1,4}$, \\ Cornelia Amălinei ${ }^{1,5}$
}

1"Grigore T. Popa" University of Medicine and Pharmacy lasi, Romania, "'Elena Doamna" Obstetrics and Gynecology University Hospital, lasi, Romania, ${ }^{3,}$ Sf. Spiridon" Clinical Emergency Hospital, lasi, Romania, ${ }^{4}$ Regional Institute of Oncology, lasi, Romania, ${ }^{5}$ Histopathology Department, Institute of Legal Medicine, lasi, Romania

\begin{abstract}
Uterine leiomyosarcoma (LMS) represents a rare tumor, accounting for $1.3 \%$ of all uterine malignancies. Although this tumor shares morphological and clinical features with other uterine benign and malignant tumors, the accurate diagnosis is necessary, due to their different biological behavior and prognosis. Therefore, we present a case of LMS in a 48 year-old patient, complaining of a 3-months metrorrhagia. The tumor presented as a poorly defined submucosal nodule, with a soft consistence and measuring $6 \mathrm{~cm}$ in diameter. The microscopic examination of this tumor nodule revealed fascicles of spindle cells, with pleomorphic hyperchromatic nuclei exhibiting moderate to severe atypia and areas of tumor necrosis. At least 5 atypical mitoses/ 10 HPF were also found. Immunohistochemistry technique, with a panel of six antibodies, comprising ER, PR, PCNA, SMA, p53, and bcl-2, has been performed for the differential diagnosis. The final histopathological diagnosis was that of uterine LMS. Considering LMS an aggressive tumor, the patient has been recommended a thorough follow-up.
\end{abstract}

Keywords: uterine leiomyosarcoma, ER, PR, PCNA, SMA, p53, bcl-2

\section{Introduction}

LMSs represent about $50 \%$ of all uterine sarcomas, being the second uterine sarcoma after carcinosarcomas and approximately $1.3 \%$ of all uterine malignancies [1, 2].

Most uterine LMSs occur in women with a median age of 50-55 years [1, 2]. Although it hasn't proved a relationship of this tumor with pregnancy or parity, the higher prevalence in women who received Tamoxifen indicates a correlation with estrogen imbalance [2]. These tumors are considered unpredictable, with a relative resistance to chemotherapy and radiotherapy [3].

Received: August 2017; Accepted after review: September 2017; Published: September 2017.

${ }^{*}$ Corresponding author: Associate Professor Raluca Balan, MD, PhD, Department of Morphofunctional Sciences I, "Grigore T. Popa" University of Medicine and Pharmacy 16 Universitatii Street, lasi 700115, Romania.

E-mail: raluca.balan@umfiasi.ro

\section{Case Report}

A 48 year-old woman presented with a 3months metrorrhagia. Her personal history and general examination were normal. Abdominal exam revealed a tender and painless $10 \mathrm{~cm}$ diameter polycyclic mass located in hypogastric region. The uterus was enlarged, with polycyclic outline, in digital vaginal exam, feature which was confirmed by ultrasound exam $(10.4 / 6.9 \mathrm{~cm})$. The laboratory findings have been that of a microcytic hypochromic anemic syndrome $(\mathrm{VEM}=76.43 / \mu \mathrm{L}, \mathrm{CHEM}=$ 24.98/pg, $\mathrm{Hb}=9.4 \mathrm{~g} / \mathrm{dl}, \mathrm{Ht}=28.3$ ) and an inflammatory syndrome $(E S R=26 \mathrm{~mm} / \mathrm{h}$, leukocytes $=16550 / \mu \mathrm{L}$ ). The clinical diagnosis was that of hemorrhagic uterine fibroid, secondary anemia, and fibrocystic breast disease. The treatment consisted of total abdominal hysterectomy with bilateral salpingo-oophorectomy. Postoperative evolution was uneventful.

Grossly, the tumor presented as a poorly defined submucosal nodule, with a soft, fleshy 
consistence, measuring $6 \mathrm{~cm}$ in diameter. On section, the tumor mass had a heterogeneous compact aspect, with whitish areas alternating with red and yellow zones.

The microscopic examination of this tumor nodule revealed fascicles of spindle cells, with pleomorphic hyperchromatic nuclei exhibiting moderate to severe atypia and areas of tumor necrosis (Figure 1). At least 5 atypical mitoses/ $10 \mathrm{HPF}$ were found and lymphovascular invasion was also registered.

The differential diagnosis was taken in consideration, to rule out the following stromal tumors: a possible atypical infarcted leiomyoma (LM), a smooth muscle tumor of uncertain malignant potential (STUMP), an endometrial stromal sarcoma, carcinosarcoma, or adenosarcoma.

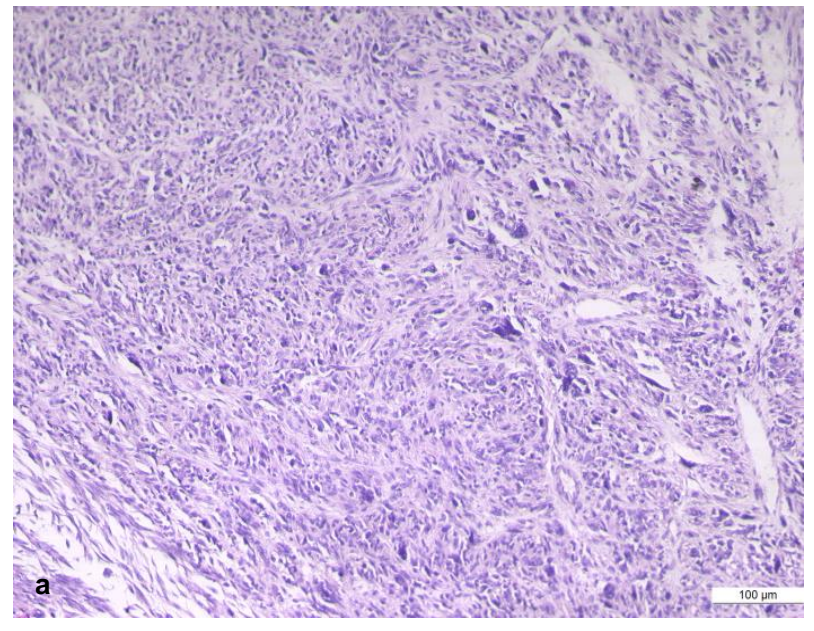

Thus, immunohistochemical technique was performed, using estrogen receptor (ER), progesterone receptor (PR), $\alpha$-smooth muscle actin ( $\alpha-S M A), B$-cell lymphoma-2 (bcl-2), proliferating cell nuclear antigen (PCNA), and protein $\mathrm{p} 53$.

ER was positive with weak intensity in about $60 \%$ of the tumor cells (Figure $2 \mathrm{a}$ ), PR was positive with high intensity in $80 \%$ of the tumor cells (Figure 2b), SMA and bcl-2 were diffusely positive (Figure2 $\mathrm{c}$ and d), PCNA was positive in about $60 \%$ of tumor cells, and p53 was positive with weak intensity in $20-30 \%$ of the tumor cells (Figure $2 \mathrm{e}$ and $\mathrm{f}$ ).

The immunohistochemical profile corroborated with clinical and histopathological data lead to the final diagnosis of uterine LMS, pT1bNxG1.

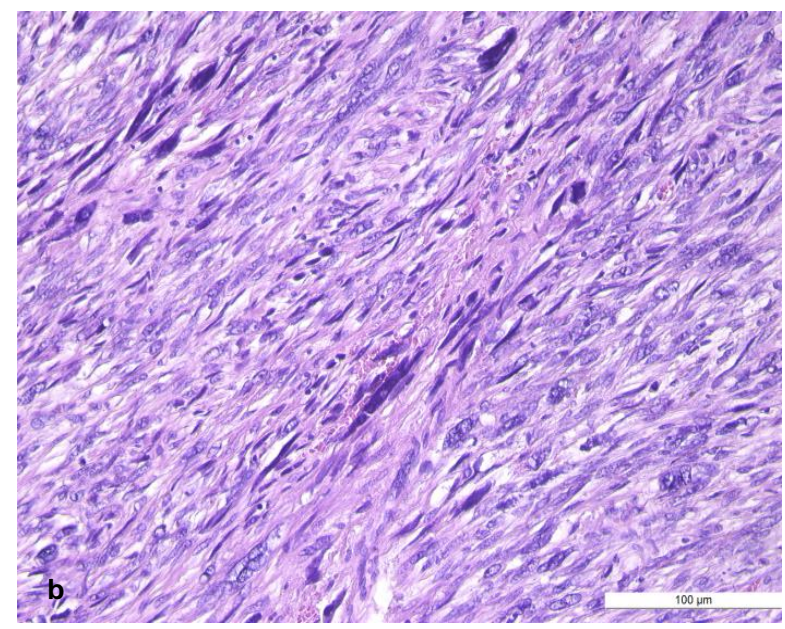

Figure 1. Uterine leiomyosarcoma, routine histological findings: a. fascicles of spindle cells with pleomorphic hyperchromatic nuclei (HE, x100), b. atypical pleomorphic and hyperchromatic nuclei of tumor cells (HE, x200)

\section{Discussions}

LMS represents about $50 \%$ of uterine sarcomas and only $1.3 \%$ of uterine malignancies [1]. The reported incidence of LMS ranges between 0.3-0.4 at 100000 women/year [4]. The median age of women diagnosed with LMS is $50-55$ years [1].

Even though the incidence is higher after age 50 , in our case the patient was 48 years old and she was premenopausal, parameters which suggest a better prognosis than for the menopausal women.
Clinically, the tumor is associated with vaginal bleeding, pain and abdominal or pelvic tumor mass, symptoms also related to leiomyoma, which make them difficult to differentiate by clinicians $[5,6]$. No relationship between the tumor development and pregnancy, parity or previous pelvic irradiation was demonstrated [1,7].

In our case, the clinical presentation was specific for a uterine tumor, but the symptoms onset was relatively recent, which is in agreement with the literature data indicating a rapid development of this tumor type [8]. 

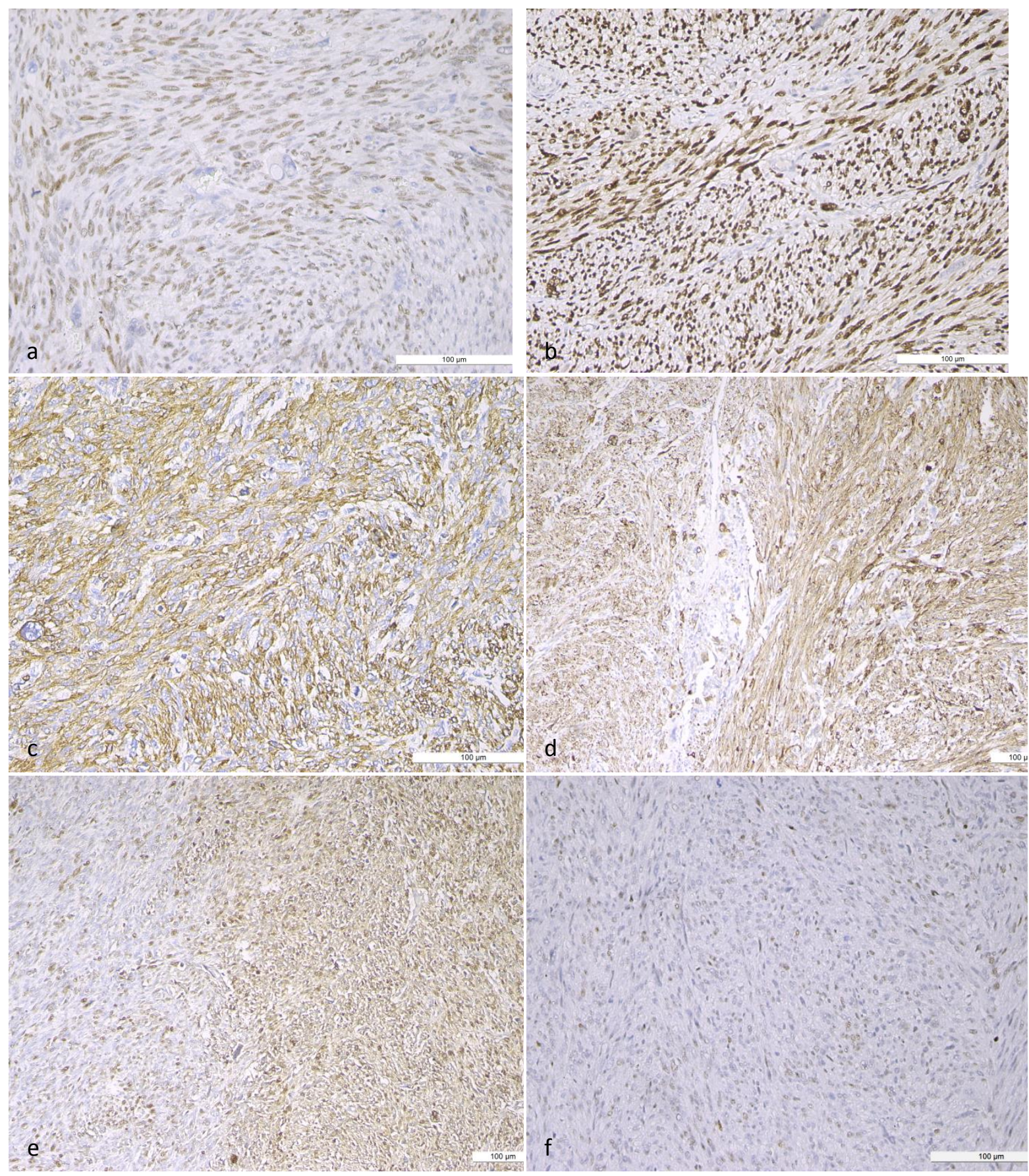

Fig. 2. Uterine leiomyosarcoma, immunohistochemical pattern: a. weak ER expression, nuclear staining in tumor cells (anti-ER Ab, x200), b. strong PR expression, nuclear staining in tumor cells (anti-PR Ab, x200), c. diffuse $\alpha-$ SMA expression, cytoplasmic staining in tumor cells (anti- $\alpha$-SMA Ab, x200), d. diffuse bcl-2 expression, cytoplasmic staining in tumor cells (anti-bcl-2 Ab, $x 100$ ), e. moderate PCNA expression, nuclear staining in tumor cells (anti-PCNA Ab, x100), f. weak p53 expression, nuclear staining in tumor cells (anti-p53 Ab, x200)

Uterine LMS's gross histological appearance is usually of a solitary tumor, often synchronous with a LM [4]. In such cases, the malignant tumor represents the largest nodule. The occurrence of other leiomyomatous uterine nodules confirms the coexistence of
LMS with leiomyomas, and thus the possibility of separate stem cell origin and/or divergent transformation pathways, leading to completely different biological behavior [9]. It is considered that most of the LMS arise without a relationship with a correspondent 
leiomyoma, less than $5 \%$ developing through malignant transformation of an existing correspondent benign smooth muscle tumor [10]. Thus, it is mandatory to sample all the uterine nodules, especially those with atypical degenerative aspects, to exclude any malignant tumor.

However, there are no specific criteria to differentiate leiomyosarcoma from benign leiomyoma prior to surgery. Although considered as not biological related, there are numerous studies which tried to differentiate a LM from a LMS on imaging, using MRI, PET or ultrasound examinations which provide no specific characteristics for a malignant tumor [10-14], and CT exam limited mainly for the evaluation of extrauterine metastases [10, 15]. These data confirm once more that the decisive and accurate diagnosis is made by histological evaluation, other methods providing only suggestive features [10].

The histopathological and immunohistochemical findings are usually validated by the rapid clinical course [8], which is in agreement with the presented case.

Usually, uterine LMS has a median diameter of $10 \mathrm{~cm}$ (only $25 \%$ are smaller than
$5 \mathrm{~cm}$ ) [2, 6]. Two thirds of tumors are located intramurally, $1 / 5$ submucosal, $1 / 10$ are subserosal, and $5 \%$ are developed in the uterine cervix [1]. On the section surface, the tumor is grey-yellow, presents irregular margins, has a soft consistency, and areas of necrosis and hemorrhage. The rare variant of myxoid LMS appears as a large, gelatinous tumor, with well-developed margins [1].

For LMS, there are 3 criteria for microscopic diagnosis: more than 5 mitoses/10 HPF, the presence of tumor necrosis, and moderate to severe cytologic atypia. The LMS histologic subtypes include epithelioid, myxoid, LMS with fusiform cells, and osteoclastic-like giant cells LMS [1], some of them histologically resembling either leiomyoma or degeneration subtypes [17]. Due to the large panel of uterine stromal tumors, the differential diagnosis was taken in consideration, to rule out a possible atypical infarcted leiomyoma (LM), a smooth muscle tumor of uncertain malignant potential (STUMP) (Table 1), an endometrial stromal sarcoma, carcinosarcoma, or adenosarcoma (Table 1) $[1,2,6]$.

Table 1. Microscopic findings useful in differential diagnosis of uterine mesenchymal tumors (adapted after [1])

\begin{tabular}{|c|c|c|c|c|c|c|}
\hline $\begin{array}{l}\text { Histological } \\
\text { criteria }\end{array}$ & LMS & $\begin{array}{c}\text { STUMP / } \\
\text { Infarcted LM }\end{array}$ & STUMP & $\begin{array}{l}\text { Atypical } \\
\text { LM }\end{array}$ & $\begin{array}{c}\text { Mitotically } \\
\text { active LM }\end{array}$ & LM \\
\hline $\begin{array}{l}\text { Nuclear } \\
\text { atypia }\end{array}$ & $\begin{array}{l}\text { Moderate-severe } \\
\text { None-mild } \\
\text { Moderate-severe }\end{array}$ & None-mild & $\begin{array}{l}\text { Moderate- } \\
\text { severe }\end{array}$ & $\begin{array}{c}\text { Focal } \\
\text { moderate } \\
\text {-severe }\end{array}$ & None-mild & $\begin{array}{l}\text { None- } \\
\text { mild }\end{array}$ \\
\hline $\begin{array}{l}\text { Tumor } \\
\text { necrosis }\end{array}$ & $+/-$ & + & - & - & - & - \\
\hline $\begin{array}{l}\text { Mitotic count } \\
\text { (per 10HPF) }\end{array}$ & $\begin{array}{l}\text { Any } \\
\geq 10\end{array}$ & $<10$ & $\begin{array}{l}\text { 5-9/ } \\
\text { atypical } \\
\text { mitoses }\end{array}$ & $<5$ & $\geq 5$ & $<5$ \\
\hline
\end{tabular}

In our case, the tumor presented spindle tumor cells, with hyperchromatic nuclei, exhibiting moderate to severe atypia, but without any particular histologic phenotype, as the above mentioned variants represent rare entities [3; 6].

Areas of necrosis and atypical mitosis (at least 5 atypical mitosis/10 HPF) were also found. As literature shows, the presence of necrosis associated with atypical mitotic activity suggest a reserved prognosis [8, 17]. These histological characteristics also represent the main histological criteria for the diagnosis of uterine LMS [18], which also differentiate this malignant tumor from a leiomyoma or a STUMP [10].

The assessment of the biological markers completed the microscopic criteria for the final histopathological diagnosis of uterine LMS. 
A particularity of our case was the association with ovarian serous cyst and endometriosis. From our knowledge, there are no data regarding the synchronicity of uterine leiomyosarcoma with ovarian endometriosis and cyst. One reason could be the rare frequency of this uterine malignant tumor. Further studies are necessary to determine if there is any biological relationship between these entities, which have different localization and behaviour. In agreement with literature data $[7,8,16,18-20]$ ER, PR, $\alpha$-SMA, PCNA, p53, and bcl-2 represent a reliable panel of antibodies for both positive and differential diagnosis of LMS with other degenerated benign and malignant uterine mesenchymal tumors.

\section{Conclusions}

Uterine LMS is a rare tumor. Although is the most frequent uterine sarcoma, second in prevalence, after carcinosarcoma, it

\section{References}

1. Zaloudek CJ, Hendrickson MR, Soslow RA. Mesenchymal tumors of the uterus. In Kurman RJ, Ellenson LH, Ronnett BM (Eds.). Blaustein's Pathology of the female genital tract. Springer; 2011:453-528.

2. Oliva $E$, Loening $T$, Carcangiu $M L$, Longacre TA, Carinelli SG, et al. Tumours of the uterine corpus. Mesenchymal tumours. In Kurman RJ, Carcangiu ML, Herrington CS, Young $\mathrm{RH}$ (Eds.) WHO Classification of tumours of female reproductive organs. IARC Press 2014:135147.

3. Setia A, Kanotra S, Aggarwal R, Bhavthankar DP. Epithelioid leiomyosarcoma of uterus. BMJ Case Rep 2012; doi:10.1136/bcr.11.2011.5144.

4. Adesiyun AG, Samaila MOA. Leiomyosarcoma uteri in a white woman. Ann Afr Med 2010; 9:35-38.

5. Oliva E. Pure mesenchymal and mixed Müllerian tumors of the uterus. In Nucci MR, Oliva E (Eds.). Gynecologic Pathology. Elsevier Churchill Livingstone; 2011:261-330.

6. D'Angelo E, Prat J. Uterine sarcomas: a review. Gynecol Oncol 2010; 116:131-139.

7. Yoshida $H$, Watanabe $M$, Shomori $K$, Ito $H$, Minamizaki T. Apoptotic cell death and p53 represents only $1-2 \%$ of all uterine malignant tumors. Once it is diagnosed, LMS needs a thorough follow-up because of its unpredictable and aggressive behavior. The histopathological differential diagnosis has to be thoroughly performed, especially when the LMS shows no specific histologic variant, because of distinctive biological character of the other presumable morphological entities.

\section{Conflict of interest/Funding Statement}

Authors do not have any potential conflict of interest or funding.

\section{Patient consent}

Written informed consent was obtained from the patient for publication of this case report and accompanying images. A copy of the written consent is available for review by the Editor-in-Chief of this journal. expression in leiomyosarcoma of soft-tissue origin. Yonago Acta Med 2001; 44:115-123.

8. Senol T, Kahramanoglu I, Muezzinoglu B, Yucesoy I. Giant leiomyosarcoma: a case report. Int J Surg Case Rep 2016; 19:109-111.

9. Danielson LS, Menendez S, Attolini CS, Guijarro MV, Bisogna M, et al. A differentiationbased microRNA signature identifies leiomyosarcoma as a mesenchymal stem cellrelated malignancy. Am J Pathol 2010; 177:908-917.

10. Shah $\mathrm{SH}$, Jagannathan JP, Krajewski $\mathrm{K}$, O'Regan KN, George S, Ramaiya NH. Uterine sarcomas: then and now. $A J R A m \quad J$ Roentgenol 2012; 199(1):213-223.

11. Tanaka $Y O$, Nishida M, Tsunoda H, Okamoto $\mathrm{Y}$, Yoshikawa $\mathrm{H}$. Smooth muscle tumors of uncertain malignant potential and leiomyosarcomas of the uterus: MR findings. $J$ Magn Reson Imaging 2004; 20(6):998-1007.

12. Cornfeld $D$, Israel $G$, Martel $M$, Weinreb J, Schwartz P, McCarthy S. MRI appearance of mesenchymal tumors of the uterus. Eur $J$ Radiol 2010; 74(1):241-249.

13. Kurjak A, Kupesic $S$, Shalan H, Jukic S, Kosuta $D$, Ilijas M. Uterine sarcoma: a report of 10 
cases studied by transvaginal color and pulsed Doppler sonography. Gynecol Oncol 1995; 59(3):342-346.

14. Umesaki N, Tanaka $T$, Miyama $M$, et al. Positron emission tomography with (18)Ffluorodeoxyglucose of uterine sarcoma: a comparison with magnetic resonance imaging and power Doppler imaging. Gynecol Oncol 2001; 80(3):372-377.

15. Murase E, Siegelman ES, Outwater EK, PerezJaffe LA, Tureck RW. Uterine leiomyomas: histopathologic features, MR imaging findings, differential diagnosis, and treatment. Radiographics 1999; 19(5):1179-1197.

16. Kelley TW, Borden EC, Goldblum JR. Estrogen and progesterone receptor expression in uterine and extrauterine leiomyosarcomas: an immunohistochemical study. Appl Immunohistochem Mol Morphol 2004; 12(4):338-341.

17. Tinelli A. Uterine leiomyosarcomas and leiomyomas: Two similar uterine solid tumors, totally different for prognosis. JST 2011; 1(2):29-33.

18. Gadducci A, Cosio S, Romanini A, Genazzani AR. The management of patients with uterine sarcoma: a debated clinical challenge. Crit Rev Oncol Hematol 2008; 65(2):129-142.

19. Bodner K, Bodner-Adler B, Kimberger O, Czerwenka K, Leodolter S et al. Estrogen and progesterone receptor expression in patients with uterine leiomyosarcoma and correlation with different clinicopathological parameters. Anticancer Res 2003; 23(1B):729-732.

20. Bodner K, Bodner-Adler B, Kimberger $O$, Czerwenka K, Mayerhofer K. Bcl-2 receptor expression in patients with uterine smooth muscle tumors: an immunohistochemical analysis comparing leiomyoma, uterine smooth muscle tumor of uncertain malignant potential, and leiomyosarcoma. J Soc Gynecol Investig 2004; 11(3):187-191. 